\title{
TUNNELING ABILITY OF SUBTERRANEAN TERMITE, Psammotermes hypostoma (DESN.) IN TREATED SOIL BY SOME INSECTICIDES GROUPS.
}

Negm, Salaw E. ; A. A. A. Said ${ }^{1}$; Y. El-Sebay ${ }^{2}$ and A.R. ElBassiouny ${ }^{2}$

1- Dept. of Pesticide, Fac. of Agric. El-Mansoura University, Egypt.

2- Dept. of Wood borers and Termite, Plant Protection Research Institute, Dokki, Giza.

\begin{abstract}
The tunneling ability of termites $P$. hypostoma (Desn.), with treated particle sizes of soil resulted that; the tunneling distance and number of branching were the highest with the large soil particle size, while was less at the small particle size treated with insecticides. The fine treated soil was more toxic and termites were died quickly in the tunnels than the coarse soil. Tunneling activity and number of branching decreased by the concentration increases. Treated soil with cypermethrin showed the highest and the more toxic to prevention of tunneling and branching followed by fipronil and chlorpyrifos, respectively. On the other hand the highly density and suitable quantity of added water to soil were the principal factors in tunneling activity. The statistics analysis resulted highly significant differences between the tested factors, (insecticides, particle sizes and concentrations), with the variable factor, (tunnel length and branches).
\end{abstract}

\section{INTRODUCTION}

Subterranean termite $P$. hypostoma represents one of the major important insects related to food kinds in the world. Termites feed mainly on cellulose; wood, papers, clothes, trees, and woody tissues of plants, buildings constructional timbers, agricultural crops, books, government records and stored products. In Egypt the considerable damage especially to rural buildings constructed with mud bricks, woodwork and furniture, causing major problems to houses and economic income. Soil treatment control methods showed failing of some chemicals applied against subterranean termite. Studies showed that termite can crossing over treated soil even with high concentration of chemicals. The present work conducted to evaluate the termite tunneling ability $P$. hypostoma (Desn.), in three particle sizes of soil treated with three insecticides groups; chlorpyrifos, fipronil and cypermethrin.

\section{MATERIALS AND METHODS}

Sandy loamy soil samples were collected from The Regional Agriculture Research Station at Ismailia Governorate. The soil samples were taken randomly from the different sites at depth of $30,60,90 \mathrm{~cm}$., where the most termite activity was carried out. Samples mixed ,homogenized for each depth, screening to three-particle sizes 850,425 and $250 \mu \mathrm{m}$ using USA Standard Testing Sieve (ASTM. E11. Specification). 
Negm S. E et al.

Soil samples were washed with tap water several times to get rid of organic matter and dirties, dried in open air and then sterilized in an electric oven at $105^{\circ} \mathrm{C}$ for 24 hours to eliminate the microorganisms' spores and vegetative stages. Samples were kept in plastic containers and placed into deep freezer for the different treatments.

To prepare a concentration of $1000 \mathrm{ppm}$ was diluted to 500,250 and $125 \mathrm{ppm}$ by untreated soil for each insecticide, a volume of $2.08 \mathrm{ml}$ of chlorpyrifos, $20.0 \mathrm{ml}$ fipronil and $10.0 \mathrm{ml}$ cypermethrin was dissolved in $200 \mathrm{ml}$ acetone. $1 \mathrm{~kg}$ of washed soil was spread on a clean stainless tray at $1 \mathrm{~cm}$ height and sprayed with formulated prepared insecticide. Treated soil was shacked by electric shaker for 48 hours. Homogenized treated soil was kept at a glass jars inside deep freezer.

Collected termites were separated from El-Sebay modified trap, 1991, and kept in incubator adjusted at $27 \mathrm{C} \circ \pm 1 \mathrm{C} \circ$. Such trap was used by El-Sebay, (1993a\&b); El-Bassiouny (2001) and Ahmed (1997 \& 2003).

\section{Tested insecticides:}

1- Organophosphates group was represented by chlorpyrifos: $O, O$-diethyl $O$ 3,5,6-trichloro-2-pyridyl phosphorothioate as Dursban.48 \%

2-Fipronil group was represented by Fipronil: \pm ( )-5-amino-1-(2,6-dichloro-á, á, á -trifluoro - $p$-tolyl) - 4 - trifluoromethylsulfinylpyrazole - 3 - carbonitrile as Termidor. $5 \%$

3- Pyrethroids group: was represented by cypermethrin: (RS)- á -cyano-3phenoxybenzyl (1RS, 3RS; 1RS, 3SR) - 3 - (2,2 - dichlorovinyl) - 2,2 dimethylcyclopropanecarboxylate

Roth: (RS)- ó -cyano-3-phenoxybenzyl (1RS)-cis-trans-3-(2,2-dichlorovinyl)2,2-dimethylcyclopropanecarboxylate as Actamethrin $10 \%$.

\section{Experiments technique:}

To study the ability of termite to overcome the treated soil and make crossing beneath treated particles, the following experiment was carried out. An apparatus designed by N. Johnson, USAD, Forest Service, USA (Jones, 1988), was adopted. The design illustrated in (Fig. ',$r$ and $r$ ). It consists of double plates of transparent plastic and is attached together with $2 \mathrm{~mm}$ distance in between, fixed in a base. At one side there is a hole $1 \mathrm{~cm}$ in diameter which fixed with $30 \mathrm{~cm}$ long of plastic tube attached with a plastic cup where $50 \mathrm{gm}$ of clean sand and a piece of cardboard $(5 \times 5 \mathrm{~cm})$. Treated soil filled the space between the double plates and moistened with $5 \mathrm{ml}$ of water. One hundred healthy workers of termites were liberated in a plastic cup, covered with led. Plates were installed on a wooden base specific for work. Daily inspection was carried out, length and number of tunnels branches were measured as termite ability for tunneling through treated soil. Such experiment and control was replicated five times for each treated soil particle size of all concentrations. Games (1990), Jones (1990), El-Sebay, (1993). Each treated soil was adopted in tunneling ability experiment.

The obtained data were analyzed using Proc ANOVA in SAS (SAS Institute 1988). 
J. Agric. Sci. Mansoura Univ., 32 (4), April, 2007

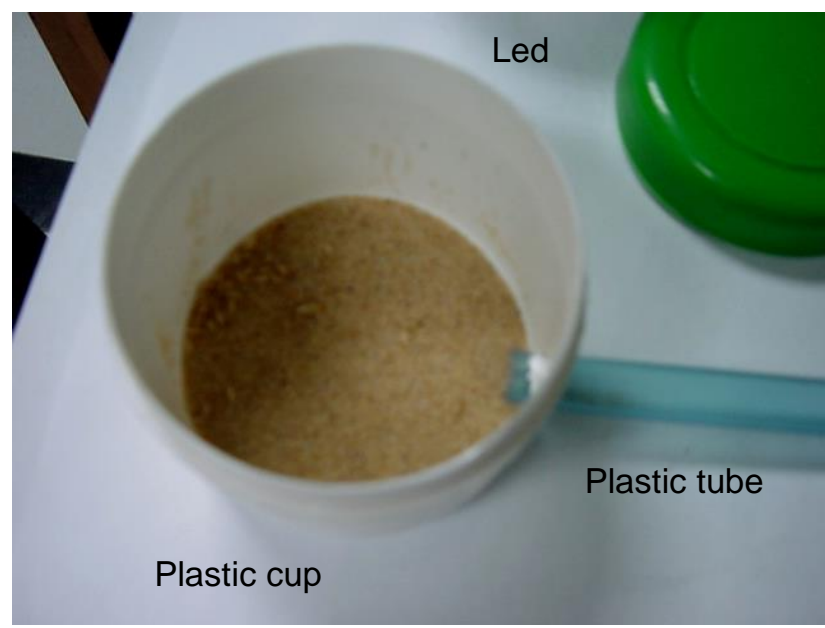

Fig. (1): Illustration of junction plastic cup and plastic tube.

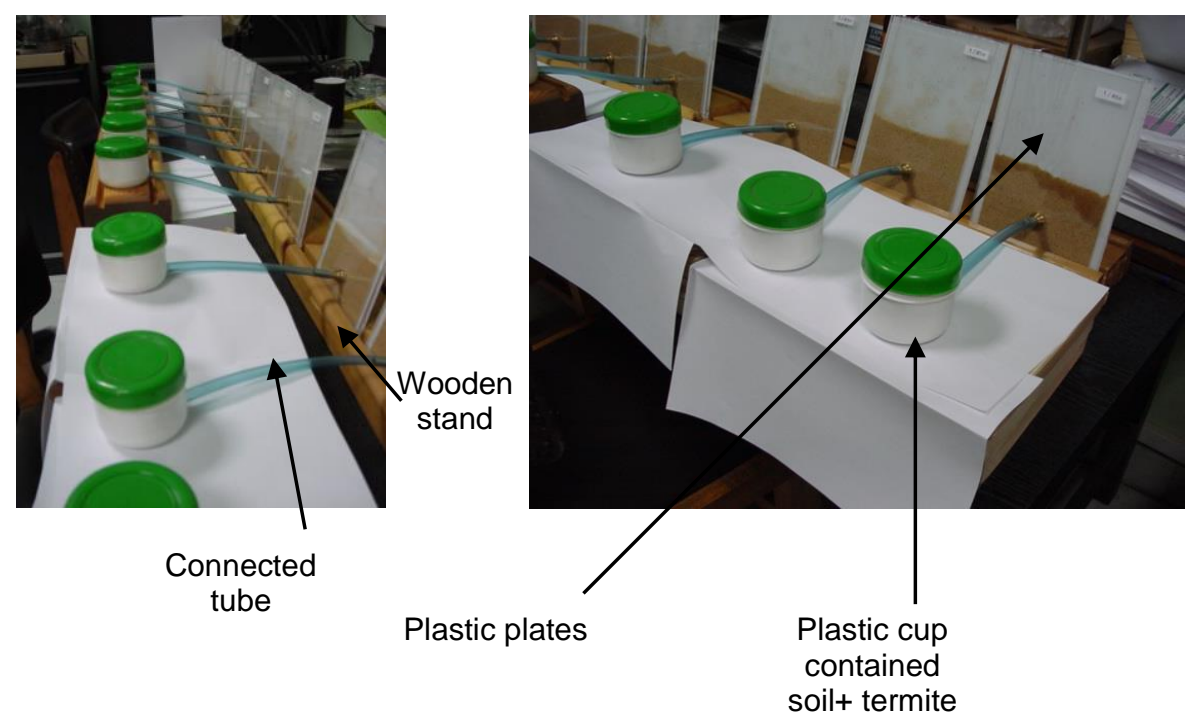

Fig. (2): Demonstrate the used materials of tunneling test. 
Negm S. E et al.

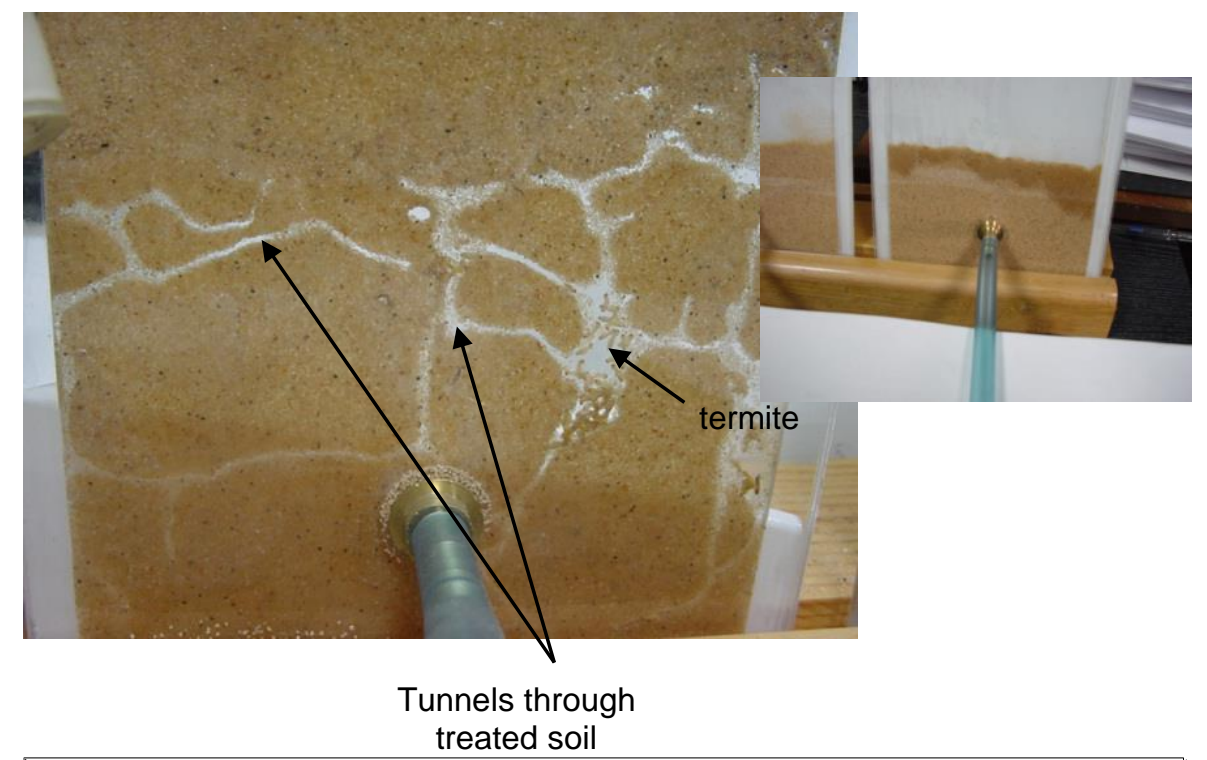

Fig. (3): Clarify of tunnels branches constructed by termites in the used plates.

\section{RESULTS AND DISCUSSION}

Tunneling ability refers to the ability of termite to penetrate treated soil and go through to construct its pathways. Tunnel branching proving termite activity and overcoming soil treated with toxicants.

Through the present study it could be assist the termite ability by number and length of tunnels constructed through treated soil as follows:

Table (1), show that at particle size $850 \mu \mathrm{m}$, the longest constructed tunnel through treated soil with chlorpyrifos, found at concentration $125 \mathrm{ppm}$ $(114.3 \mathrm{~mm})$ followed by 250,500 and $1000 \mathrm{ppm}$ (83.7, 71.4, and $33.6 \mathrm{~mm}$, respectively). The bigger number of branches (6.4) was at dose of $125 \mathrm{ppm}$ and followed by 250,500 and 1000ppm (4.6, 2.4 and 1.6, respectively).

At $425 \mu \mathrm{m}$, the longest tunnel was $78.8 \mathrm{~mm}$ followed by $68.2,57.3$ and $32.0 \mathrm{~mm}$ at concentrations of $125,250,500$ and $1000 \mathrm{ppm}$, respectively. Branching number were 4.8, 2.8, 2 and 1.2 at higher concentrations.

At $250 \mu \mathrm{m}$ particle sizes, the longest tunnels found at dose of $125 \mathrm{ppm}$, followed by $41.8,5.5$ and 0 at doses of 250,500 and $1000 \mathrm{ppm}$, respectively. Tunnels branching were 2, 1.4, 0.4 and 0 at 125, 250, 500 and 1000ppm, respectively.

Data in Table (2), soil application with fipronil, it is clear that, the longest tunnels was shown at soil treated with $125 \mathrm{ppm}$ followed by 58.4, 26 and $1 \mathrm{~mm}$ at 250,500 and $1000 \mathrm{ppm}$ in soil particle size $850 \mu \mathrm{m}$. Branches were 3.4, 3.0, 1.2 and 0.4 at different serial concentrations.

At particle size $425 \mu \mathrm{m}$, longest tunnel was noticed at soil treated with $125 \mathrm{ppm}$, followed by $40.7,25.5$, and $0.0 \mathrm{~mm}$ at 250,500 and $1000 \mathrm{ppm}$, respectively. Highest numbers of branches $(2.6,2.6,1.6$ and 0$)$ were detected at concentrations of 125, 250,500 and 1000ppm. 
Table (1): Tunneling ability of $P$. hypostoma through soil treated with different concentrations of chlorpyrifos in ppm.

\begin{tabular}{|c|c|c|c|c|c|c|c|c|c|c|}
\hline \multirow{3}{*}{ Rep. } & \multicolumn{10}{|c|}{ Soil treated with chlorpyrifos in ppm } \\
\hline & \multicolumn{2}{|c|}{125} & \multicolumn{2}{|c|}{250} & \multicolumn{2}{|c|}{500} & \multicolumn{2}{|c|}{1000} & \multicolumn{2}{|c|}{ Control } \\
\hline & $\mathbf{L}$ & $\mathbf{B}$ & $\mathbf{L}$ & $\mathbf{B}$ & $\mathbf{L}$ & $\mathbf{B}$ & $\mathbf{L}$ & $\mathbf{B}$ & $\mathbf{L}$ & B \\
\hline \multicolumn{11}{|c|}{ Particle size $850 \mu \mathrm{m}$. } \\
\hline 1 & 95.8 & 5 & 83.7 & 5 & 74.3 & 3 & 40.3 & 2 & 122.4 & 11 \\
\hline 2 & 112 & 6 & 90.4 & 6 & 66.8 & 2 & 35.2 & 1 & 163 & 12 \\
\hline 3 & 108.6 & 7 & 84.7 & 4 & 70.4 & 2 & 28.7 & 1 & 155.8 & 9 \\
\hline 4 & 107.2 & 6 & 79.5 & 5 & 69.4 & 3 & 33.4 & 2 & 170 & 13 \\
\hline 5 & 99.5 & 8 & 80.4 & 3 & 76.2 & 2 & 30.4 & 2 & 143.4 & 10 \\
\hline Mean & 114.3 & 6.4 & 83.7 & 4.6 & 71.4 & 2.4 & 33.6 & 1.6 & 150.9 & 11 \\
\hline \multicolumn{11}{|c|}{ Particle size $425 \mu \mathrm{m}$. } \\
\hline 1 & 88 & 4 & 72.3 & 3 & 60.4 & 2 & 33 & 1 & 132.6 & 10 \\
\hline 2 & 76 & 6 & 77.1 & 3 & 64.3 & 2 & 40.2 & 2 & 155.2 & 13 \\
\hline 3 & 74 & 5 & 65 & 4 & 57.4 & 3 & 39.4 & 1 & 140.5 & 10 \\
\hline 4 & 80 & 5 & 67.4 & 2 & 55 & 2 & 26.4 & 1 & 150.1 & 9 \\
\hline 5 & 76 & 4 & 58.9 & 2 & 49.5 & 1 & 22.1 & 1 & 111.4 & 8 \\
\hline Mean & 78.8 & 4.8 & 68.2 & 2.8 & 57.3 & 2.0 & 32.0 & 1.2 & 137.9 & 10.0 \\
\hline \multicolumn{11}{|c|}{ Particle size $250 \mu \mathrm{m}$. } \\
\hline 1 & 71.2 & 3 & 53.2 & 1 & 0 & 0 & 0 & 0 & 124 & 9 \\
\hline 2 & 63.2 & 2 & 49.1 & 2 & 0 & 0 & 0 & 0 & 134.1 & 10 \\
\hline 3 & 55.4 & 1 & 44 & 1 & 12 & 1 & 0 & 0 & 133.4 & 9 \\
\hline 4 & 65 & 2 & 32.1 & 2 & 15.3 & 1 & 0 & 0 & 155 & 11 \\
\hline 5 & 57.2 & 2 & 30.4 & 1 & 0 & 0 & 0 & 0 & 124.6 & 8 \\
\hline Mean & 62.4 & 2.0 & 41.8 & 1.4 & 5.5 & 0.4 & 0 & 0 & 134.2 & 9.4 \\
\hline
\end{tabular}

Table (2): Tunneling ability of $\boldsymbol{P}$. hypostoma through soil treated with different concentrations of fipronil in ppm.

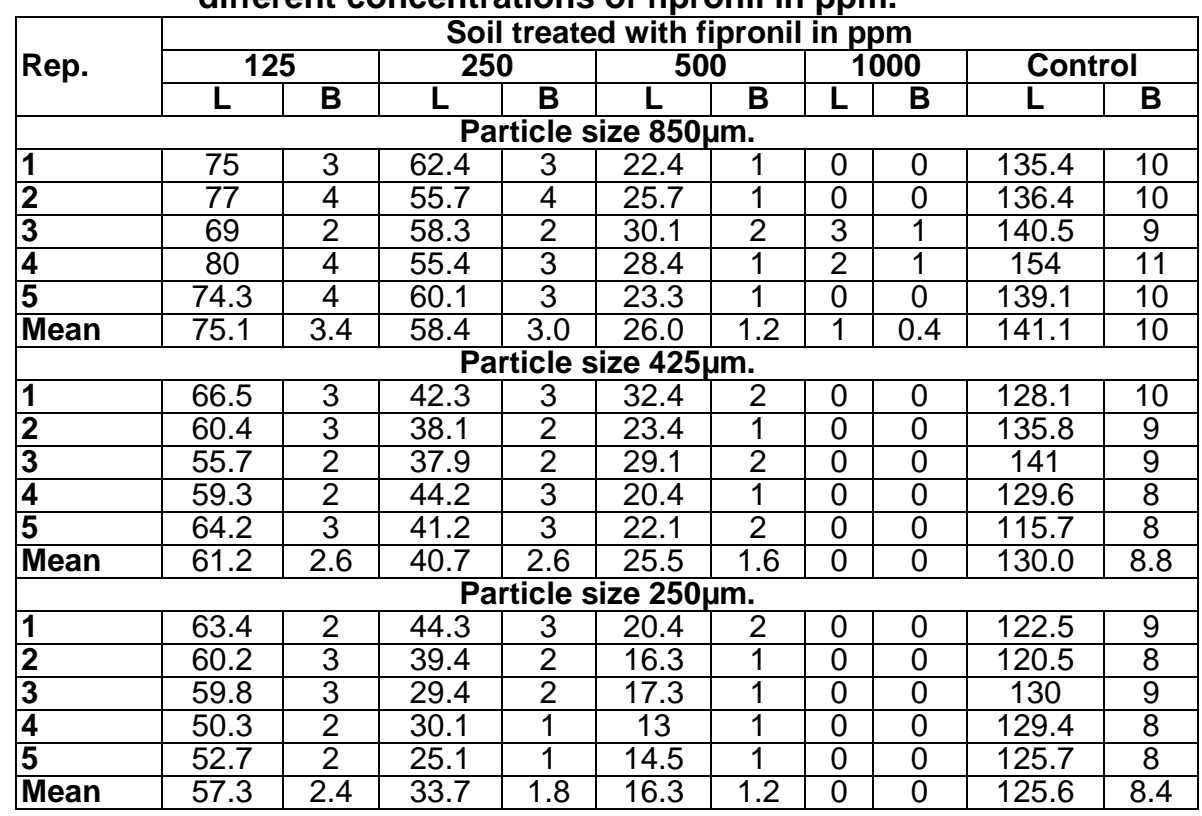


Negm S. E et al.

Also, the same results were obtained at particle size $250 \mu \mathrm{m}$. The longest tunnel $(57.3 \mathrm{~mm})$ was found at soil treated with $125 \mathrm{ppm}$ and followed by 250,500 and $1000 \mathrm{ppm}(33.7,16.3$ and $0.0 \mathrm{~mm}$, respectively). The highest numbers of branches $(2.4,1.8,1.2$ and 0$)$ were found at concentrations of $125,250,500$ and $1000 \mathrm{ppm}$, respectively.

Data in table (3), presented the longest tunnel at particle size of $850 \mu \mathrm{m}$ was found at 125ppm (48.5mm), followed by 250,500 and $1000 \mathrm{ppm}$, of cypermethrin, and represented 26.2, 17.9 and $0.0 \mathrm{~mm}$. Branches of tunnels were, 2.2, 1.2, 1 and 0 at soil treated with 125, 250, 500 and 1000ppm.

At particle size $425 \mu \mathrm{m}$, longest tunnel fond at soil treated with $125 \mathrm{ppm}$ of cypermethrin. And 29.4, 11.9 and $0.0 \mathrm{~mm}$ at soil treated with 250, 500 and $1000 \mathrm{ppm}$. Highest number of branching was $1.6 \mathrm{~mm}$ followed by $1.4,1.0$ and 0 at the higher concentrations of treated soil.

Particle size $250 \mu \mathrm{m}$ gave the same results. At 125, 250, 500 and 1000ppm tunnels length were 26.1, 7.3, 0 and 0 , respectively. At the present particle size, branches were lower, 1.4, 1.0, 0.0, 0.0 were found at 125, 250, 500 and 1000ppm.

Table (3): Tunneling ability of $\boldsymbol{P}$. hypostoma through soil treated with different concentrations of cypermethrin in ppm.

\begin{tabular}{|c|c|c|c|c|c|c|c|c|c|c|}
\hline \multirow{3}{*}{ Rep. } & \multicolumn{10}{|c|}{ Soil treated with cypermethrin in ppm } \\
\hline & \multicolumn{2}{|c|}{125} & \multicolumn{2}{|c|}{250} & \multicolumn{2}{|c|}{500} & \multicolumn{2}{|c|}{1000} & \multicolumn{2}{|c|}{ Control } \\
\hline & $\mathbf{L}$ & B & $\mathbf{L}$ & B & $\mathbf{L}$ & B & $\mathbf{L}$ & B & $\mathbf{L}$ & B \\
\hline \multicolumn{11}{|c|}{ Particle size $850 \mu \mathrm{m}}$. \\
\hline 1 & 60.4 & 2 & 32.2 & 1 & 18.7 & 1 & 0 & 0 & 154 & 10 \\
\hline 2 & 61.2 & 2 & 25.5 & 1 & 20.4 & 1 & 0 & 0 & 143.2 & 8 \\
\hline 3 & 49.7 & 3 & 29.4 & 2 & 21.3 & 1 & 0 & 0 & 160.4 & 9 \\
\hline 4 & 44.6 & 2 & 20.4 & 1 & 17.4 & 1 & 0 & 0 & 120.8 & 10 \\
\hline 5 & 46.5 & 2 & 23.4 & 1 & 11.5 & 1 & 0 & 0 & 144.7 & 10 \\
\hline Mean & 48.5 & 2.2 & 26.2 & 1.2 & 17.9 & 1.0 & 0 & 0 & 144.6 & 9.4 \\
\hline \multicolumn{11}{|c|}{ Particle size $425 \mu \mathrm{m}$. } \\
\hline 1 & 53.2 & 2 & 29.4 & 1 & 12.4 & 1 & 0 & 0 & 130.4 & 10 \\
\hline 2 & 43.2 & 2 & 30.2 & 2 & 16.3 & 1 & 0 & 0 & 151.2 & 10 \\
\hline 3 & 47.9 & 1 & 32.1 & 2 & 11.4 & 1 & 0 & 0 & 136.7 & 9 \\
\hline 4 & 39.4 & 1 & 30.1 & 1 & 10.4 & 1 & 0 & 0 & 155 & 9 \\
\hline 5 & 34.6 & 2 & 25.1 & 1 & 9.1 & 1 & 0 & 0 & 124.3 & 10 \\
\hline Mean & 43.7 & 1.6 & 29.4 & 1.4 & 11.9 & 1.0 & 0 & 0 & 139.4 & 9.6 \\
\hline \multicolumn{11}{|c|}{ Particle size $250 \mu \mathrm{m}}$. \\
\hline 1 & 28.4 & 1 & 9.4 & 1 & 0 & 0 & 0 & 0 & 118.7 & 7 \\
\hline 2 & 33.2 & 1 & 3.2 & 1 & 0 & 0 & 0 & 0 & 132.4 & 10 \\
\hline 3 & 21.4 & 1 & 8.4 & 1 & 0 & 0 & 0 & 0 & 133.7 & 9 \\
\hline 4 & 25.4 & 2 & 6.2 & 1 & 0 & 0 & 0 & 0 & 128.9 & 9 \\
\hline 5 & 22.3 & 2 & 9.1 & 1 & 0 & 0 & 0 & 0 & 127.6 & 10 \\
\hline Mean & 26.1 & 1.4 & 7.3 & 1.0 & 0 & 0 & 0 & 0 & 128.3 & 9.0 \\
\hline
\end{tabular}

Generally, as shown data in Table (4), revealed that, at all particle size of tested soil the longest tunnel was at soil treated with $125 \mathrm{ppm}$ and decreased by the concentration increases. The highest length tunnel was 
$114.3 \mathrm{~mm}$, followed by $83.7 \mathrm{~mm}$ in soil treated with $250 \mathrm{ppm}$ at the same particle size $(850 \mu \mathrm{m})$, while the least length $(0.0 \mathrm{~mm})$ were almost at all soil treated with $1000 \mathrm{ppm}$ except in case of chlorpyrifos (850 and $425 \mu \mathrm{m})$ and fipronil $(850 \mu \mathrm{m})$.

Data showed that termite can penetrate soil treated with chlorpyrifos more than fipronil and the least tunneling ability was found at all concentrations of cypermethrin. Also, branching was correlated with tunneling action, more long tunnel more branching.

On the other hand, tunneling and branching through soil with particle size of $850 \mu \mathrm{m}$ or more is prevailing and vice versa. Consequently, soil treated with pyrethroids showed more prevention against termite activity.

Finally, Termites tunneling ability with treated particle size of soil indicated that the tunneling and branching were the highest with the coarse treated soil, while were the least with the fine soil. So the fine treated soil was more toxic and termites were died quicker in the tunnels than the coarse soil. Tunneling activity and branching, decreased by the concentration increases. Soil treated with Pyrothroids group (cypermethrin) showed the best and the more toxic to prevention of tunneling and branching followed by Fipronil group (Fipronil) and Organophosphate group (Chlorpyrifos), respectively. The highly density and suitable quantity of water added to soil were the principal factors in tunneling activity.

The authors suggest that, the Pyrothroids group (Cypermethrin) could be the superior in the termite control of the invested wooden furniture, buildings and constructions or mixed with concrete.

The obtained results are in agreement with Galal (1982), who mentioned that the chlorpyrifos was used and succeeded to prevent tunneling activity of subterranean termites $P$. hypostoma.

Data are in agreement with Tamashiro (1989), research on Coptotermes formosanus, he mentioned that, chlorpyrifos forms an effective barrier in sand and clay to prevent soil penetrated for at least 5 years.

Also data are agree with the finding of Jones (1990), who showed that, the termites were constructed a greater number of tunnels of greater length at the high population density. At a high population density, $C$. formosanus may be able to bridge a termiticidal barrier, when compared among the three termiticides (Chlordane, Chlorpyrifos and Permethrin).

Data are agree with Gahlhoff (2001), Tested the ability of Subterranean termite Reticulitermes flavipes (Kollar) on the penetration, and data revealed that the termite penetrated only a few millimeters into 500ppm Dursban TC- treated soil at all thickness and the termites penetrating completely through 5.0 and $0.5 \mathrm{ppm}$ treatment.

Houseman (2003), investigated the effect of soil texture, soil moisture, and termite density on the rate of tunnel construction in $R$. flavipes. Tunneling rate and tunnel morphology were measured in laboratory arenas by simulating a thin slice of subterranean habitat. Tunneling rates were faster in arenas containing soils with higher sand concentrations. High termite densities had little effect on tunneling rates in small gallery systems. The rate of tunnel construction along edges of tunneling arenas was significantly 
greater than in the interior. Tunneling distance in days after the addition of water was higher than in days prior to adding water.

Laura (2005), examined the insecticides Fipronil against the Formosan subterranean termite, Coptotermes formosanus, (Sheraki) and Eastern subterranean termite, Reticulitermes flavipes, (Koller). Data indicated that the Fipronil provided an effective barrier against tested termites. Soil was penetrated to some degree at all concentrated of tested pesticide, indicated that, Fipronil showed similar toxicity for both species. Higher mortality prevented termites from penetrating the entire $5 \mathrm{~cm}$ of treated soil.

Table (4): Tunneling ability of $P$. hypostoma through soil treated with different concentrations of three insecticides in $\mathrm{ppm}$ at different particle size of soil.

\begin{tabular}{|c|c|c|c|c|c|c|c|c|c|c|c|}
\hline \multirow{3}{*}{ Chemical } & \multirow{3}{*}{$\begin{array}{c}\text { Particle } \\
\text { size in } \\
\mu \mathrm{m} .\end{array}$} & \multicolumn{10}{|c|}{ Soil treated with ppm } \\
\hline & & \multicolumn{2}{|c|}{125} & \multicolumn{2}{|c|}{250} & \multicolumn{2}{|c|}{500} & \multicolumn{2}{|c|}{1000} & \multicolumn{2}{|c|}{ Control } \\
\hline & & $\mathbf{L}$ & B & $\mathbf{L}$ & B & $\mathbf{L}$ & B & $\mathbf{L}$ & B & $\mathbf{L}$ & B \\
\hline \multirow{3}{*}{ Chlorpyrifos } & 850 & 114.3 & 6.4 & 83.7 & 4.6 & 71.4 & 2.4 & 33.6 & 1.6 & 150.9 & 11.0 \\
\hline & 425 & 78.8 & 4.8 & 68.2 & 2.8 & 57.3 & 2.0 & 32.0 & 1.2 & 137.9 & 10.0 \\
\hline & 250 & 62.4 & 2.0 & 41.8 & 1.4 & 5.5 & 0.4 & 0 & 0 & 134.2 & 9.4 \\
\hline \multirow{3}{*}{ Fipronil } & 850 & 75.1 & 3.4 & 58.4 & 3.0 & 26.0 & 1.2 & 1.0 & 0.4 & 141.1 & 10.0 \\
\hline & 425 & 61.2 & 2.6 & 40.7 & 2.6 & 25.5 & 1.6 & 0 & 0 & 130.0 & 8.8 \\
\hline & 250 & 57.3 & 2.4 & 33.7 & 1.8 & 16.3 & 1.2 & 0 & 0 & 125.6 & 8.4 \\
\hline \multirow{3}{*}{ Cypermethrin } & 85 & 48.5 & 2.2 & 26.2 & 1.2 & 17.9 & 1.0 & 0 & 0 & 144.6 & 9.4 \\
\hline & 42 & 43.7 & 1.6 & 29.4 & 1.4 & 11.9 & 1.0 & 0 & 0 & 139.4 & 9.6 \\
\hline & 250 & 26.1 & 1.4 & 7.3 & 1.0 & 0 & 0 & 0 & 0 & 128.3 & 9.0 \\
\hline
\end{tabular}

Statistics analysis:

Data in table (5), clarified that, the mean of treatments with chlorpyrifos, fipronil and cypermethrin, were recorded 71.467, 52.793 and 41.553 respectively, for variable $L$. and recorded $4.0000,3.1600$ and 2.5867 for variable B., highly significant (F. values recorded for both variables 24.85 and 16.32 respectively). In the same trend the means of particle sizes, were $66.180,57.067$ and 42.567 for variable L. and recorded 3.8533, 3.3333 and 2.5600 for variable B., the F. values recorded highly significant 15.44 and 13.68 for variable L. and B. respectively. The mean's concentrations were counted 63.044, 43.267, 25.756, 7.400 and 136.889 for 125, 250, 500, $1000 \mathrm{ppm}$ and control respectively, and the F. value recorded highly significant variation 163.76 for variable L., also, 2.9777, 2.2000, 1.2000, 0.3556 and 9.5111 for the concentration and the $\mathrm{F}$. value recorded highly significant variation 256.53 , for variables $B$. 
Table (5): Illustration of significantly variables between the tested factors, insecticides, particle sizes and concentrations with the variables, tunnel length and branches.

\begin{tabular}{|c|c|c|c|c|c|c|c|}
\hline \multirow{2}{*}{ Variable } & \multicolumn{5}{|c|}{ The mean of treatments } & \multirow{2}{*}{$\begin{array}{c}\text { F. Value } \\
0.5 \%\end{array}$} & \multirow{2}{*}{$\operatorname{Pr}>\mathrm{F}$} \\
\hline & \multicolumn{2}{|c|}{ Chlorpyrifos } & Fipronil & \multicolumn{2}{|c|}{ Cypermethrin } & & \\
\hline L. & \multicolumn{2}{|c|}{71.467} & 52.793 & \multicolumn{2}{|c|}{41.553} & $24.85^{\star \star}$ & 0.0001 \\
\hline \multirow[t]{3}{*}{ B. } & \multicolumn{2}{|c|}{4.0000} & 3.1600 & \multicolumn{2}{|c|}{2.5867} & $16.32^{\star \star}$ & 0.0001 \\
\hline & \multicolumn{5}{|c|}{ The mean of particle sizes } & & \\
\hline & \multicolumn{2}{|c|}{$850 \mu \mathrm{m}$} & $425 \mu \mathrm{m}$ & \multicolumn{2}{|c|}{$250 \mu \mathrm{m}$} & & \\
\hline L. & \multicolumn{2}{|c|}{66.180} & 57.067 & \multicolumn{2}{|c|}{42.567} & $15.44^{\star \star}$ & 0.0001 \\
\hline \multirow[t]{3}{*}{ B. } & 3.8 & 533 & 3.3333 & & 600 & $13.68^{* *}$ & 0.0001 \\
\hline & \multicolumn{5}{|c|}{ The mean of concentrations in ppm } & & \\
\hline & 125 & 250 & 500 & 1000 & Control & & \\
\hline L. & 63.044 & 43.267 & 25.756 & 7.400 & 136.889 & $163.76^{\star *}$ & 0.0001 \\
\hline B. & 2.9777 & 2.2000 & 1.2000 & 0.3556 & 9.5111 & $256.53^{\star \star}$ & 0.0001 \\
\hline
\end{tabular}

\section{REFERENCES}

Ahmed, H. M. (1997): Ecological studies and control of harvester subterranean termite, Anacanthotermes ochracious (Burm.), at Fayoum Gov. M.Sc.Thesis Cairo University, Fayoum. PP. 66.

(2003): Ecological and control studies on Cairo subterranean termites under Fayoum conditions Ph.D degree Thesis University, Fayoum. PP. $127-128$.

El-Bassiouny, A. R. (2001): A study on the ecology and biological control of subterranean termites M. Sc. Thesis, Fac. Agric. Al-Azhar Univ. 145 p.

El-Sebay, Y. (1991): A modified trap for El-Sebay subterranean termites. Fourth Arab Cong. of Plant Protection, Cairo, 1-5 Dec. 1991.

(1993a): Ecological studies on the colony of the harvester termite, A. ochraceus (Burm.) in Egypt. Bull. Soc. Ent. Egypt, Econ. Ser., 20: 1-9.

(1993b): Ecological studies on the subterranean termites harvester A. ochraceus (Burm.) in Egypt. Assuit J. Agric. Sci., 24 (4): 35-47.

(1993): Evaluation of soil treatment with certain insecticides for subterranean termite control. Bull. Ent. Soc. Egypt. Econ. Ser. 20 (47): $47-58$.

Gahlhoff, J.E. Jr. and PG. Koehler (2001): Penetration of the eastern subterranean termite into soil treated at various thickness and concentrations of Dursban TC and Premise 75. Journal-of-EconomicEntomology. 94: 2, 486-491. Record 149 of 165 - CAB Abstracts 2002/08-2003/10.

Galal A; A. Salman, M. M. Hossein, M. A. Morsy and A. A. El-Sayed (1982): Preliminary report on the control of subterranean termites in Egypt. Assiut J. Agric. Scie., 13 (3): 229-246.

Games L. Smith and Michal K. Rust (1990): Tunneling response mortality of western subterranean termite (Isoptera: Rhinotermitidae and), to soil treated with termiticides. J. Econ. Entomol. 84(1): 1396 - 1401. 
Negm S. E et al.

Houseman, R.M and Gold, R.E. (2003): Factors that influence tunneling in the eastern subterranean termite, Reticulitermes flavipes (Kollar) (Isoptera: Rhinotermitidae). J. Agric. Urban Entomology. 20(2): 69-81.

Jones S. C. (1988): Tunneling ability of subterranean termites through termiticides-treated soil. (Proceedings, Nineteenth Annual Meeting of the International Res. Group on Wood preservation, 1988, April, Madrid, Spain Document No. IRG/WP/1375.9 P).

(1990): Effects of population density on tunneling by Formosan subterranean termite (Isoptera: Rhinotermitidae) through treated soil. J. Econ. Entomol. Vol. 83 No. 3: $875-878$.

Laura N. Remen and Nan-yao Su (2005): Time trends in mortality for Thiamethoxam and Fipronil against Formosan Subterranean termites and Eastern Subterranean termites (Isoptera: Rhinotermitidae) J. of Econ. Entomol. Vol. 98 No. 3 pp. 911 - 915.

SAS Institute (1988), SAS user's guide: Statistics. SAS Institute, Cary, N.C.

Tamashiro-M; Yates-JR; Ebesu-RH; Yamamoto-RT; Su-NY; Bean-JN. (1989): Dursban TC insecticide as a preventive treatment for Formosan subterranean termite in Hawaii. Down-to-Earth. 45: 2, 1-5; 7 ref. Record 49 of 165 - CAB Abstracts 1990-1991.

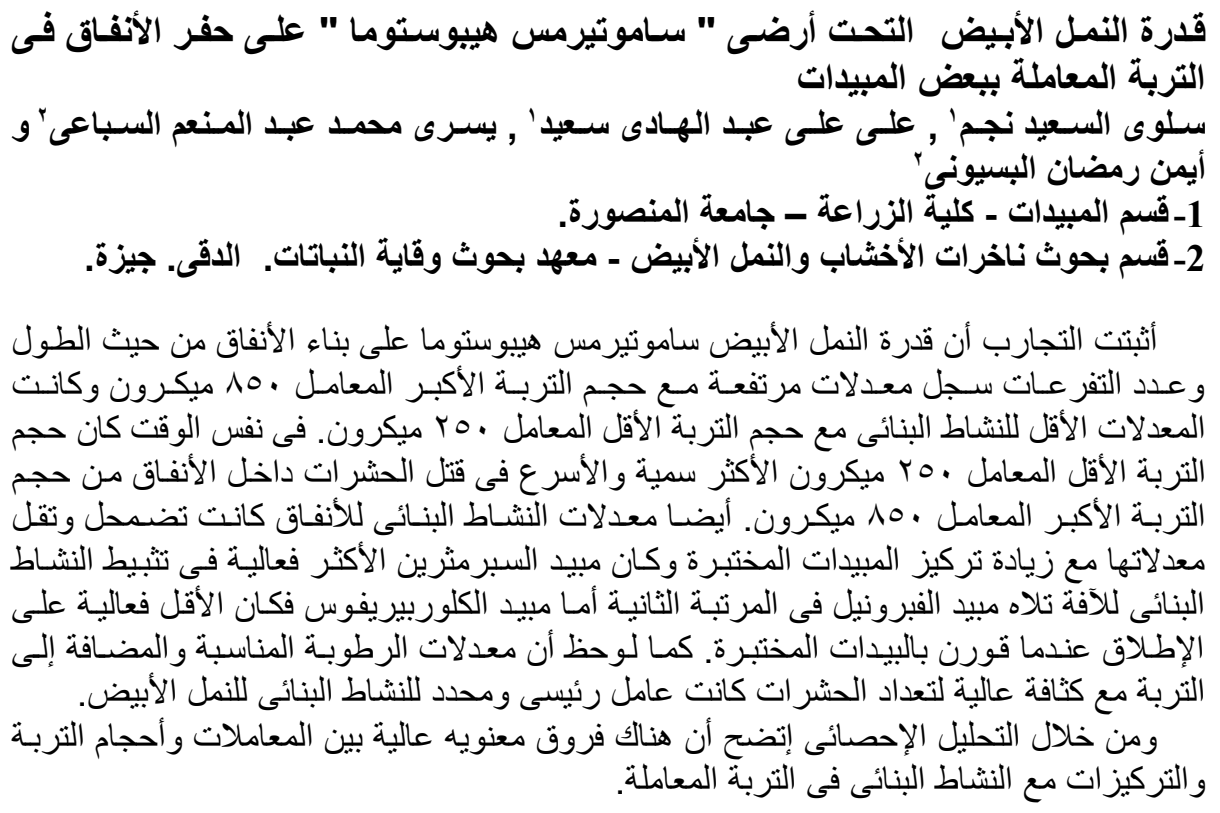

